\title{
Age Wise Comparative Study on Temperament among Twins in Bagar Zones, India
}

\author{
Reetu Devi ${ }^{1^{*}}$ and Vijay Kumar ${ }^{2}$ \\ ${ }^{1}$ Department of Human Development and Family Studies (HDFS), CCS HAU, Hisar, India \\ ${ }^{2}$ Director (FM), SNIATTE, CCS, Haryana Agricultural University, Hisar, India
}

*Corresponding author

Keywords

Temperament, Age,

Behaviour,

Observation,

Personality traits,

Environment

Article Info

Accepted:

04 October 2019

Available Online:

10 November 2019
Age is the length of time that a person has lived or a thing has existed. Temperament refers to our inborn personality traits, which are genetic in nature. The different ways infants interact with and react to their environment and experiences are reflective of their temperament, or behavioral style. The present study was conducted in four districts namely; Hisar Fatehabad, Rohtak and Jind of Haryana state with the purpose of availability of maximum numbers of twins in the required age group. A sample of 104 pairs of twins in the age group of $6-10$ years will be taken for the sample. Temperament was taken as dependent variable and age was taken as independent variable. The Malhotra Temperament Schedule (MTS) developed by Malhotra and Malhotra (1988) was used to assess child's temperament and self developed scheduled was used to assess the age of children. Result revealed that in bagar zone mean score shows that the twins from age group of 8 to 10 years was better on sociability, emotionality, energy, distractibility, rhythmcity and on total temperament compares to the age group of 4 to 8 years old twins.

\section{Introduction}

Age is the length of time that a person has lived or a thing has existed. Making informal learning work results presupposes not only using technology effectively, but also taking advantage of the influences exerted by various components of the environment in which indirectly induced knowledge is acquired, without prior planning but which impacts and is incorporated into the mode Of thinking and acting. Peter et al., (2010) compared 525 monozygotic (MZ) and 200 same- sex dizygotic (DZ) twin pairs.

Almost $80 \%$ of the twins were female, and their age varied widely around a mean of 32 years. The result indicated that $\mathrm{MZ}$ twins 
shown more similar experiences than DZ twins and were also more alike in their temperament.

The study of temperament is a recent and rapidly growing area in psychology as the role of temperament in influencing developmental pathways and outcomes has now been recognised.

Extreme difficult temperament is often viewed as a risk factor for later behaviour problems (Hill, 2012). Temperament is observable early in human ontogeny, hinting at genetic influences (Zentner and Bates, 2008). Temperament defined as person emotional and behavioural modes of response to environmental events (Shaffer and Kipp, 2007)

Children are born with their natural style of interacting with or reacting to people, places and things. This natural behaviour style in everyday situations is known as temperament. Temperament refers to our inborn personality traits, which are genetic in nature. The different ways infants interact with and react to their environment and experiences are reflective of their temperament, or behavioral style.

Temperament is an individual's innate style of responding to the environment in both behavioural and emotional ways (Griggs et al., 2009). All children have a temperament that will influence their emotions and how they adapt to change in their environments (Steinberg, 2014). Temperamental stability is influenced by both biological and environmental factors, as well as cultural factors in some cases.

\section{Objectives}

Compare the temperament according to their age among twins' children in bagar zone.

\section{Materials and Methods}

The present study was conducted in four districts namely; Hisar Fatehabad, Rohtak and Jind of Haryana state with the purpose of availability of maximum numbers of twins in the required age group of $4 \quad-10$ years identified under UGC project of the department.. From these two zones villages were selected on the basis of availability of twins in the required age groups. A sample of 200 pairs of twins in the age group of $6-10$ years will be taken. The dimensions of temperament will be assessed individually. A variable is the set of value that forms a classification. A value is anything which can be predicted. There were two types of variables in the study i.e. independent and dependent variable. Temperament was taken as dependent and age was taken as independent variable. The Malhotra Temperament Schedule (MTS) developed by Malhotra and Malhotra (1988) was used to assess child's temperament self developed scheduled was used to assess the age of children.

\section{Results and Discussion}

\section{Age wise mean comparison of twins on temperament dimension in Bagar zone}

In bagar zone mean score shows that the twins from age group of 8 to 10 years was better on sociability $\quad(11.89 \pm 1.24), \quad$ emotionality (7.42 \pm 0.99$)$, energy (7.93 \pm 1.04$)$, distractibility (4.09 \pm 0.50$)$, rhythmicity $(4.22 \pm 0.51)$ and on total temperament $(35.61 \pm 2.83)$ compares to the age group of 4 to 8 years old twins.

It was concluded that In bagar zone mean score shows that the twins from age group of 8 to 10 years was better on sociability, emotionality, energy, distractibility, rhythmicity and on total temperament compares to the age group of 4 to 8 years old 
twins. Saudino et al., (2004) tested the validity of parents' perceptions of their children's temperamental differences (mean age of 7.6 years). Parents reported that their children as having opposite temperaments for activity level and shyness, the examiners rated substantial similarity between sibling temperaments. They suggested that parents have a tendency to exaggerate sibling differences in temperament, which leads to contrast effects between siblings. Also, some dimensions seemed to be less affected by contrast effects than others such as approach, fear, low pleasure, smiling and laughter, and perceptual sensitivity (Fig. 1 and Table 1).

Table.1 Age wise mean comparison of twins on temperament dimension in Bagar zone

\begin{tabular}{|l|l|l|l|l|}
\hline Dimension of temperament & $\begin{array}{l}(\mathbf{n}=62) \\
\text { Mean } \pm \text { SD }\end{array}$ & $\begin{array}{l}(\mathbf{n}=\mathbf{4 2}) \\
\text { Mean } \pm \text { SD }\end{array}$ & Z value & $\begin{array}{l}(\mathbf{n}=104) \\
\text { Mean } \pm \text { SD }\end{array}$ \\
\hline Sociability & $11.01 \pm 1.24$ & $11.89 \pm 1.24$ & $3.55^{* *}$ & $11.45 \pm 1.46$ \\
\hline Emotionality & $7.39 \pm 0.99$ & $7.42 \pm 0.99$ & 0.15 & $7.84 \pm 1.15$ \\
\hline Energy & $7.35 \pm 0.85$ & $7.93 \pm 1.04$ & $2.99^{*}$ & $7.26 \pm 1.13$ \\
\hline Distractibility & $3.75 \pm 0.63$ & $4.09 \pm 0.50$ & $3.06^{* *}$ & $3.90 \pm 0.79$ \\
\hline Rhythmicity & $3.85 \pm 0.55$ & $4.22 \pm 0.51$ & $3.51^{* *}$ & $3.96 \pm 0.64$ \\
\hline Total Temperament & $33.38 \pm 2.45$ & $35.61 \pm 2.83$ & $4.16^{* *}$ & $34.44 \pm 3.39$ \\
\hline
\end{tabular}

Fig.1 Age wise mean comparison of twins on temperament in Bagar zone

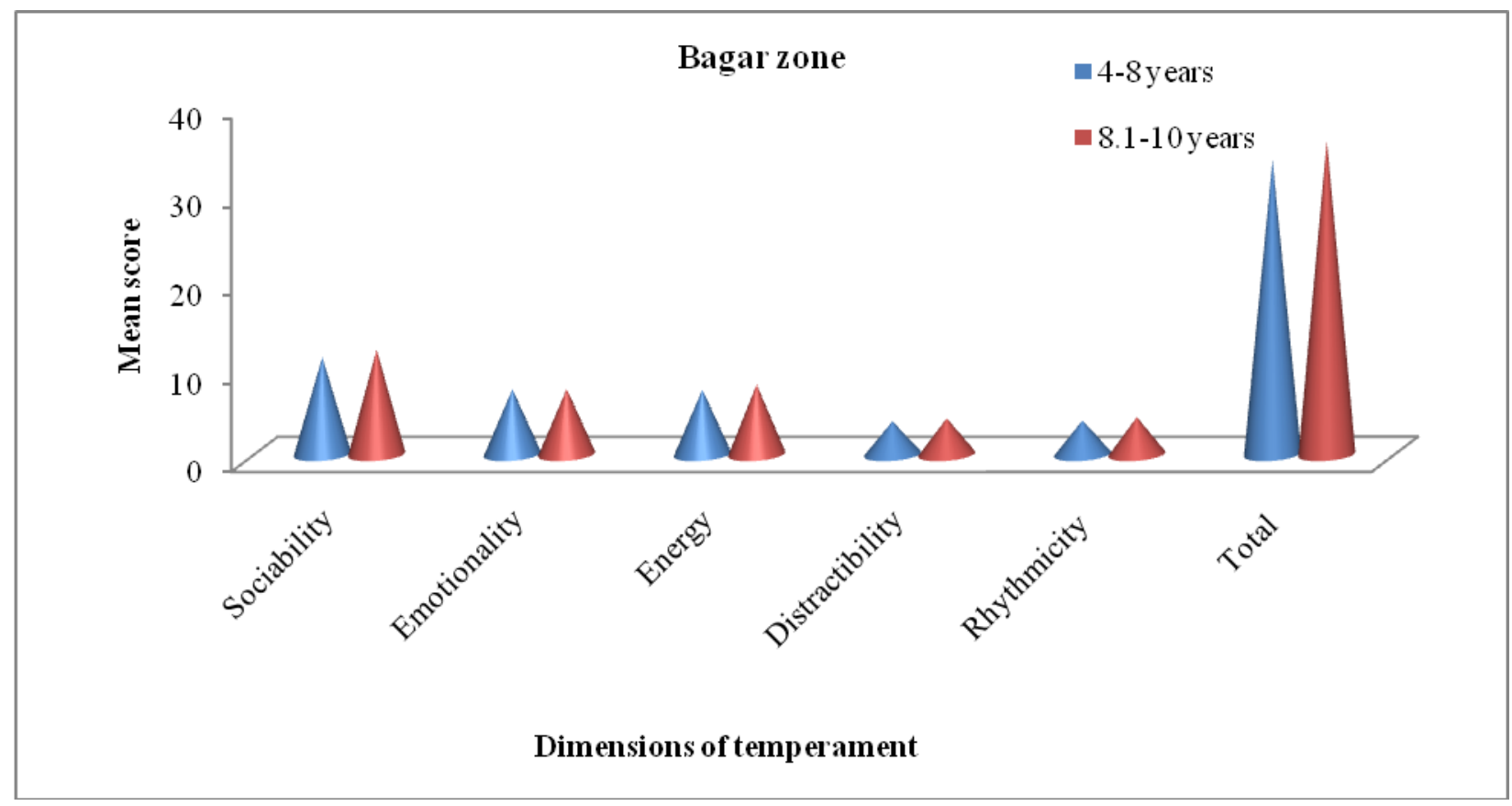


References

Anonymous. 2011. Temperament and Parenting - Temperament.com. Retrieved from https://www.bdi.com/temperament. comfaqs.html

Griggs, M. S., Gagnon, S.G., Huelsman, T. J., Kidder-Ashley, P. and Ballard, M. 2009. Student-teacher relationships matter: Moderation influences between temperament and preschool social competence. Psychology in the Schools. 46 : 553-566.

Hill, J. 2012. Biological, psychological and social processes in the conduct disorders. Journal of Child Psychology and Psychiatry, 43:133-165.

Johnson, W., Krueger, R. F., Bouchard, T. J. Jr. and McGue, M. 2011. The personalities of twins: Just ordinary folks. Twin Research, 5:125-131.

Kagan, J., Snidman, N., Zentner, M. R., and Peterson, E. 2005. Infant temperament and anxious symptoms in school age children. Development and Psychopathology, 11: 209-224.

Lamb, M. E., Chuang, S. S., Wessels, H., Broberg, A. G. and Hwang, C. P. 2012. Emergence and construct validation of the Big Five factors in early childhood: a longitudinal analysis of their ontogeny in Sweden. Child Development, 73:1517-24.

Saudino, K. J., Wertz, A. E., Gagne, J. R., and Chawla, S. 2004. Night and day: Are siblings as different in temperament as parents say they are? Journal of Personality and Social Psychology, 87: 698-706.

Shaffer, R., and Kipp S., 2007. Mothers' appraisal of goodness of fit and children's social development. International Journal of Behavioural Development. http://jbd.sagepub.com.

Steinberg, L. 2014. The 10 basic principles of good parenting. New York, NY: Simon \& Schuster Paperbacks.

\section{How to cite this article:}

Reetu Devi and Vijay Kumar. 2019. Age Wise Comparative Study on Temperament among Twins in Bagar Zones, India. Int.J.Curr.Microbiol.App.Sci. 8(11): 289-292. doi: https://doi.org/10.20546/ijcmas.2019.811.036 